\title{
The Impact of Dialysis Modality on Left Ventricular Function in Patient with End Stage Kidney Disease
}

\author{
Maskey A, Paudel N, Sapkota S, Jha P \\ Department of Medicine, Manipal Teaching Hospital, Pokhara, Nepal
}

Received: September 15, 2020

Accepted: December 5, 2020

Published: December 30, 2020

Cite this paper:

Maskey A, Paudel N, Sapkota S, Jha P. The Impact of Dialysis Modality on Left Ventricular Function in Patient with End Stage Kidney Disease. Nepal Journal of Medical Sciences 2020;5(2):2-9. http://dx.doi.org/10.3126/njms. v5i1.36704

\begin{abstract}
Introduction: Cardiovascular disease is frequent in end-stage kidney disease patients, and is a major cause of morbidity and mortality. This study was carried out to assess the comparative cardiac effects of hemodialysis and continuous ambulatory peritoneal dialysis on left ventricular function.
\end{abstract}

Methods: A prospective observational study was carried out in patients undergoing hemodialysis or continuous ambulatory peritoneal dialysis at least for 6 months. The duration of the study was from June 2019 to May 2020. CAPD consists of 3 to 4 exchanges/day and haemodialysis 2-3 times/week for 4 hours. Baseline characteristics age, gender, dialysis duration, hypertension, diabetes and hyperlipidaemia were collected. The same cardiologist performed all echocardiography at the end of hemodialysis session in hemodialysis patients and after the drain of dialysate in peritoneal dialysis patients.

Results: Sixty patients (40 hemodialyses, 20 peritoneal dialyses) were enrolled. The mean age of the patient was $53.71 \pm 13.00$ years (range 25-76). There was a slightly higher number of male in the hemodialysis group $(\mathrm{p}=0.065)$. Systolic and diastolic blood pressure were significantly higher in hemodialysis groups $(\mathrm{p}<0.001)$. Regarding left ventricular parameters, hemodialysis patients had a higher prevalence of left ventricular diastolic dysfunction, left ventricular hypertrophy, left ventricular mass compared to peritoneal dialysis patients. Pericardial effusion and thickening were present higher in hemodialysis patients and was statistically significant $(\mathrm{p}<0.05)$.

Conclusion: The modality of dialysis influenceleft ventricular function. Left ventricle dysfunction is prevalent among hemodialysis patients compared to peritoneal dialysis. Echocardiographic follow up is essential as this could improve the management of cardiovascular complications in dialysis patients.

Keywords: Hemodialysis; Left Ventricular Function; Peritoneal Dialysis

Correspondence to: Dr. Abhishek Maskey

Department of Medicine

Manipal Teaching Hospital, Pokhara, Nepal

Email: maskey21@hotmail.com

Licensed under CC BY 4.0 International License which permits use, distribution and reproduction in any medium, provided the original work is properly cited 


\section{INTRODUCTION}

Patients with end-stage kidney (ESKD) disease undergoing either haemodialysis (HD) or continuous ambulatory peritoneal dialysis (PD) more often have the problems of hypertension and vascular stiffness. Cardiovascular disease in these population continues to contribute to mortality and morbidity. Disorders of left ventricular (LV) geometry and function are highly prevalent and leads to increased mortality in this highly vulnerable population. ${ }^{1}$ In the dialysis population left ventricular dysfunction is common with a rate $10-30$ times greater than that in the general population. ${ }^{2} \mathrm{LV}$ dysfunction is often preceded by left ventricular hypertrophy $(\mathrm{LVH})$ that in itself carries a poor prognostic value for mortality in patients with ESKD. ${ }^{3}$

This study aims to evaluate the effects of two different methods of renal replacement therapy (chronic haemodialysis and continuous ambulatory peritoneal dialysis) on left ventricular parameters.

\section{METHODS}

A prospective observational study was carried out in patients undergoing hemodialysis and continuous ambulatory peritoneal dialysis from June 2019 to May 2020 in Manipal Teaching Hospital. Patients on renal replacement therapy for at least 6 months were included in our study. PD consists of 3 to 4 exchanges/day with 2 litres of fluid. Patient undergoing HD 2-3 times a week for 4 hours with standard bicarbonate dialysate were included in our study. Patients with a history of malignancy, rheumatic heart disease, congenital heart disease, previous cardiac surgery, or previous renal transplantation and who had been on dialysis for less than 6 months were excluded from the study. This study was conducted after the approval by the Institutional Review Committee of the Manipal College of Medical Sciences. All patients signed an informed consent form before any data were collected. Baseline characteristics were collected: age, gender, dialysis duration, hypertension and lipid profile. Routine laboratory methods were used to measure biochemical parameters: haemoglobin, serum uricacid, phosphorus and calcium levels. Blood pressure was measured in a supine position after a fifteen-minute rest with a mercury sphygmomanometer and a cuff of appropriate size in the arm without arteriovenous fistula. Phase I and V of the Korotkoff sounds were taken respectively as systolic blood pressure (SBP) and diastolic blood pressure (DBP). Three consecutive measurements were derived in every patient, and the arithmetic mean was calculated as the final value.

Hypertension is defined as systolic blood pressure (BP) $\geq 140 \mathrm{mmHg}$, diastolic BP $\geq 90 \mathrm{mmHg}$ or the use of antihypertensive medication.

Hyperlipidaemia is defined as total cholesterol (TC) $\geq 200 \mathrm{mg} / \mathrm{dl}$, low-density lipoprotein cholesterol (LDL-C) $\geq 130 \mathrm{mg} / \mathrm{dl}$ or the use of lipid-lowering medication. Anaemia is defined as haemoglobin $<11 \mathrm{~g} / \mathrm{dl}$.

\section{Dialysis Prescription:}

All HD patients received a four-hour HD session two- three $(n=7)$ times/ week using a Gambro AK98 (Baxter Gambro, Sweden). The ion concentrations in the dialysate were $\mathrm{Na}+138 \mathrm{mmol} / \mathrm{L}, \mathrm{K}+2.0 \mathrm{mmol} / \mathrm{L}, \mathrm{Ca} 2+$ $1.5 \mathrm{mmol} / \mathrm{L}, \mathrm{Mg} 2+1.0 \mathrm{mmol} / \mathrm{L}, \mathrm{CL}-109$ $\mathrm{mmol} / \mathrm{L}$, and $\mathrm{HCO} 3-35 \mathrm{mmol} / \mathrm{L}$, respectively. Meanwhile, PD patients were treated by 3-4 $(n=2)$ exchanges/ day using a standard glucose-based dialysate ( $\mathrm{PH} 5.2, \mathrm{Na}+132$ $\mathrm{mmol} / \mathrm{L}, \mathrm{Ca} 2+1.75 \mathrm{mmol} / \mathrm{L}, \mathrm{Mg} 2+0.25$ $\mathrm{mmol} / \mathrm{L}, \mathrm{CL}-96 \mathrm{mmol} / \mathrm{L}$, Lactate $40 \mathrm{mmol} / \mathrm{L}$; Dianeal $^{\oplus}$, Baxter Healthcare Inc., Philippines)

\section{Echocardiographic Data:}

Echocardiography was performed in both HD and PD patients who were undergoing dialysis for at least 6 months duration. The same cardiologist performed all echocardiographic examinations at the end of the HD session in hemodialysis patients and after the drain of dialysate in PD patients. Baseline and follow up echocardiography were not performed in this study. The patients were examined in the 
left lateral decubitus position and data were collected in standard parasternal long-axis, short-axis, and apical views. Measurements were acquired by averaging three cardiac cycles. $\mathrm{LVH}$ is defined by an increase in left ventricle mass (LVM) index $>102 \mathrm{~g} / \mathrm{m}^{2}$ for men and $>88 \mathrm{~g} / \mathrm{m}^{2}$ for women. ${ }^{4} \mathrm{LVM}$ is considered as severely abnormal if LVM $\geq 122$ $\mathrm{g} / \mathrm{m}^{2}$ in women and $\geq 149 \mathrm{~g} / \mathrm{m}^{2}$ in men. The following anatomically validated equation is used to estimate LVM: LVM $=0.8$ [1.04(IVS + LVIDd + LVPW)3 - LVIDd3] + 0.6; where IVS is the diastolic septal thickness, LVIDd is the diastolic dimension of the LV cavity and LVPW is the diastolic thickness of the posterior wall. ${ }^{4}$ Teicholz's and Simpson's methods are used to evaluate LV ejection fraction. Echocardiographic maximum left atrial volume is measured from apical 4 - and 2 -chamber views by biplane area length. ${ }^{6,7}$ The values of the $\mathrm{E}$ wave and $\mathrm{A}$ wave of mitral flow was collected (on apical 4-chamber view, a $3 \mathrm{~mm}$, at the level of the basal mitral annulus). Tissue Doppler velocities of longitudinal mitral annular motion were measured in the median and lateral segment of the basal mitral annulus (on apical 4-chamber view) and the mean e' (early diastolic velocity) was used to estimate E/e'. Peak systolic velocity (S), early (e') diastolic velocities were assessed for the right and left annular side, successively.

Data were analyzed by SPSS 20.0 (IBM Corp., USA). Measurement data are reported as means SD and the differences were measured by the t-test. Enumeration data are reported as percentage or rate, and the differences were compared with the $\mathrm{Chi}^{2}$ test. A p-value $<0.05$ was considered to be significant.

\section{RESULTS}

Sixty patients (40 undergoing HD, 20 undergoing PD) were enrolled in this study. Demographic characteristics of different groups are shown in Table-1. Routine biochemical parameters were performed and depicted in Table-1. The mean age of the patient in our study was $53.71 \pm 13.00$ years (range 25-76). There were a slightly higher number of male in HD group compared to PD group but was not statistically significant ( $\mathrm{p}=$ 0.065 ). Patients on HD were on dialysis for a longer period, $34.72 \pm 9.15$ months, compared to PD patients $28.10 \pm 6.81$ months $(\mathrm{p}<0.05)$. $\mathrm{HD}$ and PD patients did not differ regarding diabetes and hypertension, serum calcium level, serum phosphorus and haemoglobin level. HD patients showed significantly lower total cholesterol (TC), lower high-density lipoprotein (HDL) and triglyceride (TG) levels. Systolic blood pressure and diastolic blood pressure were significantly higher in HD groups.

LV parameters of both $\mathrm{HD}$ and $\mathrm{PD}$ groups were compared and depicted in Table-2. Regarding LV parameters, HD patients had higher interventricular septum thickness in diastole (IVSd) $13.61 \pm 1.59 \mathrm{~mm}$, compared to $\mathrm{PD}$ patients $11.60 \pm 1.23 \mathrm{~mm}(\mathrm{p}<0.001)$. HD patients had high interventricular septal thickness during systole (IVSs) $15.20 \pm$ $1.66 \mathrm{~mm}$ compared to PD patients $13.33 \pm$ $2.63 \mathrm{~mm}(\mathrm{p}<0.001)$. All $40 \mathrm{HD}$ patients had $\mathrm{LVH}$ while only $16 \mathrm{PD}$ patients had LVH $(\mathrm{p}<0.001)$. Pericardial effusion and thickening were present higher in HD patients than PD patients and was statistically significant $(\mathrm{p}<0.05)$.

Table 1: Baseline characteristics of the study population

\begin{tabular}{lccc}
\multicolumn{1}{c}{ Dialysis modality } & $\begin{array}{c}\text { Peritoneal dialysis } \\
\mathbf{N}=\mathbf{2 0}\end{array}$ & $\begin{array}{c}\text { Hemodialysis } \\
\mathbf{N = 4 0}\end{array}$ & p-value \\
\hline Age & $46.6 \pm 13.14$ & $57.27 \pm 11.39$ & 0.002 \\
Male gender (\%) & $8(40)$ & $26(65)$ & 0.065 \\
Duration of RRT (months) & $28.10 \pm 6.81$ & $34.72 \pm 9.15$ & 0.006 \\
Hypertension (\%) & $18(90)$ & $38(95)$ & 0.46 \\
Diabetes mellitus (\%) & $6(30)$ & $17(42)$ & 0.34 \\
Total cholesterol (mg/dl) & $196.52 \pm 10.74$ & $144 \pm 30.53$ & 0.001
\end{tabular}




\begin{tabular}{lccc} 
High density lipoprotein $(\mathrm{mg} / \mathrm{dl})$ & $46.75 \pm 4.02$ & $38 \pm 12.20$ & 0.001 \\
Triglyceride $(\mathrm{mg} / \mathrm{dl})$ & $123.6 \pm 10.74$ & $94.60 \pm 24.49$ & 0.001 \\
S. Uric acid $(\mathrm{mg} / \mathrm{dl})$ & $10.84 \pm 15.77$ & $5.26 \pm 2.41$ & 0.03 \\
S. Calcium $(\mathrm{mg} / \mathrm{dl})$ & $8.19 \pm 0.51$ & $8.22 \pm 1.16$ & 0.89 \\
S. Phosphorus $(\mathrm{mg} / \mathrm{dl})$ & $5.85 \pm 0.63$ & $6.9 \pm 2.03$ & 0.32 \\
Haemoglobin $(\mathrm{gm} / \mathrm{dl})$ & $9.56 \pm 1.15$ & $9.10 \pm 1.23$ & 0.16 \\
Systolic blood pressure $(\mathrm{mm} \mathrm{Hg})$ & $140.7 \pm 13.25$ & $158.3 \pm 9.99$ & 0.001 \\
Diastolic blood pressure $(\mathrm{mm} \mathrm{Hg})$ & $79.6 \pm 6.08$ & $95.8 \pm 6.08$ & 0.001 \\
\hline
\end{tabular}

Table: 2 Left ventricular parameters in $H D$ and $P D$ patients

\begin{tabular}{|c|c|c|c|c|}
\hline \multicolumn{2}{|c|}{ Dialysis modality } & $\begin{array}{l}\text { Peritoneal dialysis } \\
\qquad \mathrm{N}=\mathbf{2 0}\end{array}$ & $\begin{array}{l}\text { Hemodialysis } \\
\qquad \mathbf{N}=\mathbf{4 0}\end{array}$ & p-value \\
\hline \multirow[t]{3}{*}{ Lvdd grade } & Grade -1 & 11 & 21 & 0.61 \\
\hline & Grade-2 & 8 & 14 & \\
\hline & Grade-3 & 1 & 5 & \\
\hline \multirow[t]{3}{*}{ LVH } & Normal & 4 & 0 & 0.001 \\
\hline & Concentric & 15 & 14 & \\
\hline & Eccentric & 1 & 26 & \\
\hline \multicolumn{2}{|l|}{ IVS d (mm) } & $11.60 \pm 1.23$ & $13.61 \pm 1.59$ & 0.001 \\
\hline \multicolumn{2}{|l|}{ LVidd (mm) } & $49.96 \pm 7.77$ & $57.39 \pm 11.26$ & 0.03 \\
\hline \multicolumn{2}{|c|}{ LVPW d (mm) } & $12.25 \pm 1.50$ & $13.57 \pm 1.64$ & 0.04 \\
\hline \multicolumn{2}{|c|}{ LV mass (gm) } & $243.69 \pm 67.27$ & $348.09 \pm 72.46$ & 0.001 \\
\hline \multicolumn{2}{|l|}{ IVS s (mm) } & $13.33 \pm 2.63$ & $15.20 \pm 1.66$ & 0.001 \\
\hline \multicolumn{2}{|c|}{ LVids (mm) } & $34.26 \pm 4.90$ & $40.84 \pm 9.78$ & 0.005 \\
\hline \multicolumn{2}{|c|}{ LVPW s (mm) } & $18.55 \pm 1.56$ & $17.55 \pm 1.79$ & 0.03 \\
\hline \multicolumn{2}{|l|}{ LVEF (\%) } & $59.8 \pm 5.59$ & $55.6 \pm 11.43$ & 0.12 \\
\hline \multicolumn{2}{|c|}{ Left atrium (mm) } & $35.32 \pm 6.56$ & $42.90 \pm 6.18$ & 0.001 \\
\hline \multicolumn{2}{|l|}{ Aortic root } & $31.10 \pm 6.56$ & $33.57 \pm 6.18$ & 0.12 \\
\hline \multicolumn{2}{|c|}{ Mitral valve (thickened) (\%) } & $7(35)$ & 19(47) & 0.35 \\
\hline \multicolumn{2}{|c|}{$\begin{array}{l}\text { Pulmonary artery pressure }(\mathrm{mm} \\
\mathrm{Hg})\end{array}$} & $33.65 \pm 16.35$ & $39.9 \pm 18.08$ & 0.16 \\
\hline \multicolumn{2}{|c|}{ Pericardial thickening (\%) } & $0(0)$ & 19(47) & 0.001 \\
\hline \multicolumn{2}{|c|}{ Pericardial effusion(\%) } & $7(35)$ & $28(70)$ & 0.01 \\
\hline
\end{tabular}

LVDD: Left ventricular diastolic dysfunction; LVH: left ventricular hypertrophy; IVSd: interventricular septum in diastole; LVidd: Left ventricular internal diameter in diastole; LVPWd: Left ventricular posterior wall diastole, LV mass: left ventricular mass; IVSs: interventricular septum in systole; LVids: Left ventricular internal diameter in systole; LVPWs: left ventricular posterior wall in systole; LVEF: ejection fraction.

\section{DISCUSSION}

The present study was done to document the magnitude of LV dysfunction in the patient with dialysis. To the best of our knowledge, this study is among the first to report LV dysfunction among ESKD patients under dialysis in our country. This study adds the existing knowledge on cardiovascular disease in the patient on dialysis.

Our patients on PD were typically younger than patients on HD. Similar findings were seen in a study conducted by Sharabas et al. and 
Goodkin et al. in other parts of the world. ${ }^{5,6}$ In general, in Nepal most patients prefer HD compared to PD. There is selection bias in favour of HD: patients who began dialysis on HD because of life-threatening circumstances did not change for PD.

Studies performed regarding the frequency and significance of cardiometabolic syndrome in PD patients, dyslipidemia develops in most of the patients. ${ }^{7}$ In our study between the dialysis patient's groups, TC, HDL and LDL levels were significantly higher in PD. This higher level of cholesterol in PD patients might have been due to glucotoxic effects caused by glucose-based solution used in PD patients. Similar findings were observed by Harmankaya et al. and Holmes et al. in other studies. ${ }^{8.9}$ In our study mean value of SBP and DBP were significantly lower in PD patients compared with HD patients. On contrary, a study conducted by Lai et al. showed PD patients had a higher frequency of arterial hypertension. ${ }^{10}$ These findings in our study might be due to the adequate hydration state of PD patients by using higher osmotic PD solution on needful patients to achieve dry weight.

LVDD is present in all patients with chronic kidney disease, including those with an early stage of the disease. LVDD got worsened in parallel with the severity of kidney dysfunction. ${ }^{11}$ LVDD has been observed in patients receiving RRT for ESKD. ${ }^{12,13}$ In our study, LVDD was markedly increased in HD patients compared to the PD group. A similar higher frequency of LVDD in HD patient was seen in a study done by Paneni et al. ${ }^{14}$ However, Lee et al. ${ }^{15}$ showed the prevalence and severity of diastolic LV dysfunction was higher in PD patients.

$\mathrm{LVH}$ is an independent risk factor for mortality and cardiovascular events which is present in up to $85 \%$ of dialysis patients. ${ }^{16} \mathrm{LVH}$ is detected in $60 \%-90 \%$ of patients in renal replacement therapy. ${ }^{17}$ Increases in LV mass represent a stronger predictor for mortality and cardiovascular complications. ${ }^{3}$ In the present study we found that LVH and LVM were higher in HD group than PD patients and was statistically significant. Similar findings of a high prevalence of LVH in HD patients were seen in a study done by Kimura et al. ${ }^{13}$, and Tian et al. ${ }^{18}$ On the contrary, a study was done by Ellouli et al. ${ }^{19}$ showed a higher prevalence of LVH in PD patients. Our study contradicts earlier data by Enia et al. showing higher prevalence of LVH and LVM in PD patients. ${ }^{20}$ This difference can be explained by higher age and higher frequency of arterial hypertension in HD patients in our study.

Reduced LVEF is closely associated with increased adverse events and a strong predictor of death from cardiovascular events as well as all-cause mortality in dialysis patients. ${ }^{2,21}$ Comparative study done by Refaat et al. ${ }^{22}$ on hemodialysis and peritoneal dialysis patients showed that LVEF more than $53 \%$ was found to be cardioprotective. In our study, HD patients displayed a significantly lower value of ejection fraction than a patient undergoing PD patients. Our findings are consistent with findings observed in the study done by Paneni et al. ${ }^{14}$

Our results indicate that the incidence of pericardial thickening and effusion is significantly higher in HD patients than in PD patients. Similar findings were observed in a study done by Alpert et al. ${ }^{23}$ However, Ellouali et al, showed a higher frequency of pericardial effusion in their study. ${ }^{19}$ The reason for the higher incidence of effusion can be caused by fluid overload with or without congestive heart failure in HD patients, a situation unlikely to develop during effective CAPD. It is also possible that CAPD provides better clearance than hemodialysis of toxins potentially responsible for pericarditis in renal failure.

The present study had some limitations that should be discussed. First, it is a single-centre study with a small sample size which may have precluded us from finding a real difference. As the acceptance trend of the patient for PD is less compared to HD modality worldwide, our study included a small number of PD patients compared to HD group. Second, we were not able to perform baseline echocardiography in 
studied patients before the commencement of dialysis treatment which could have shown a better impact of dialysis treatment modality in left ventricular function. Finally, while ambulatory blood pressure monitoring may be a better marker of cardiac load in HD patients than pre-and post- HD blood pressure measurements, we did not use it in the present study. ${ }^{24}$

\section{CONCLUSION}

The method of dialysis seems to influence LV function. Our study showed a higher prevalence of LV dysfunction in hemodialysis patients compared to peritoneal dialysis patients. Hence, echocardiographic follow up is essential as this could improve the management of cardiovascular complications in dialysis patients.

\section{CONFLICT OF INTEREST}

None

\section{SOURCES OF FUNDING}

None

\section{REFERENCES}

1. Sood MM, Pauly RP, Rigatto C, Komenda P. Left ventricular dysfunction in the haemodialysis population. NDT Plus.2008;1(4):199-205.https://doi. org/10.1093/ndtplus/sfn074

2. Zoccali C, Benedetto FA, Mallamaci F, Tripepi G, Giacone G, Stancanelli B et al. Left ventricular mass monitoring in the follow-up of dialysis patients: prognostic value of left ventricular hypertrophy progression. Kidney Int. 2004;65(4):1492-98. https://doi. org/10.1111/j.1523-1755.2004.00530.x

3. Devereux RB, Alonso DR, Lutas EM, Gottlieb GJ, Campo E, Sachs I et al. Echocardiographic assessment of left ventricular hypertrophy: comparison to necropsy findings. Am $J$ Cardiol. 1986;57(6):450-58. $\quad$ https://doi. org/10.1016/0002-9149(86)90771-X

4. Lang RM, Bierig M, Devereux RB,
Flachskampf FA, Foster E, Pellikka PA et al. Recommendations for chamber quantification: a report from the American Society of Echocardiography's Guidelines and Standards Committee and the Chamber Quantification Writing Group, developed in conjunction with the European Association of Echocardiography, a branch of the European Society of Cardiology. $\mathrm{J} \mathrm{Am}$ Soc Echocardiogr. 2005;18(12):1440$63 . \quad$ https://doi.org/10.1016/j. echo.2005.10.005

5. Sharabas I, Siddiqi N. Cardiovascular disease risk profiles comparison among dialysis patients. Saudi J Kidney Dis Transpl. 2016;27:692-700. https://doi. org/10.4103/1319-2442.185225

6. GoodkinDA, Bragg-GreshamJL, Koenig $\mathrm{KG}$, Wolfe RA, Akiba T, Andreucci $\mathrm{VE}$ et al. Association of comorbid conditions and mortality in hemodialysis patients in Europe, Japan, and the United States: The dialysis outcomes and practice patterns study (DOPPS). $J$ Am Soc Nephrol. 2003;14:3270$7 . \quad$ https://doi.org/10.1097/01. ASN.0000100127.54107.57

7. Huang JW, Yang CY, Wu HY, Liu KL, Su $\mathrm{CT}, \mathrm{Wu} \mathrm{CK}$ et al. Metabolic syndrome and abdominal fat are associated with inflammation, but not with clinical outcomes, in peritoneal dialysis patients. Cardiovasc Diabetol. 2013;12:86. https://doi.org/10.1186/1475-2840-12$\underline{86}$

8. Harmankaya O, Akalin N, Akay $\mathrm{H}$, Okuturlar Y, Erturk K, Kaptanogullari $\mathrm{H}$ et al. Comparison of risk factors for cardiovascular disease in hemodialysis and peritoneal dialysis patients. Clinics (Sao Paulo). 2015;70(9):601-5. https:// doi.org/10.6061/clinics/2015(09)01

9. Holmes CJ. Glucotoxicity in Peritoneal Dialysis-Solutions for the Solution!. Adv Chronic Kidney Dis. 2007;14(3):269$78 . \quad$ https://doi.org/10.1053/j. ackd.2007.03.009

10. Lai S, Molfino A, Russo GE, Testorio 
M, Galani A, Innico $G$ et al. Cardiac, Inflammatory and Metabolic Parameters: Hemodialysis versus Peritoneal Dialysis. Cardiorenal Med. 2015;5(1):20-30. https://doi.org/10.1159/000369588

11. Sidmal PS, HP M, KC S. Pattern and severity of left ventricular diastolic dysfunction in early and end stage renal disease patients with or without dialysis in rural population in South India. Int $J$ Biomed Res. 2015;6(8):546-55. https:// doi.org/10.7439/ijbr.v6i8.2358

12. Günal AI, Ilkay E, Kirciman E, Karaca I, Dogukan A, Celiker H. Blood pressure control and left ventricular hypertrophy in long-term CAPD and hemodialysis patients: a cross-sectional study. Perit Dial Int. 2003;23(6):563-7. https://doi. org/10.1177/089686080302300608

13. Kimura H, Takeda K, Tsuruya K, Mukai H, Muto Y, Okuda H et al. Left ventricular mass index is an independent determinant of diastolic dysfunction in patients on chronic hemodialysis: a tissue Doppler imaging study. Nephron Clin Pract. 2011;117(1):67-73. https:// doi.org/10.1159/000319649

14. Paneni F, Gregori M, Ciavarella GM, Sciarretta S, Tocci G, Palano F et al. Impact of dialysis modality on the appropriateness of left ventricular mass in patients with end-stage renal disease. Int J Cardiol. 2011;149(2):250-2. https:// doi.org/10.1016/j.ijcard.2011.02.030

15. Lee JK, Lin HH, Tsai CT, Chen JJ, Kuo CC, Lien YC et al. Differential association of proinflammatory cytokines with left ventricular diastolic dysfunction in subjects with and without continuous ambulatory peritoneal dialysis. Nutr Metab Cardiovasc Dis 2012; 22(11): 974-80. https://doi. org/10.1016/j.numecd.2011.01.001

16. Bansal N, Keane M, Delafontaine P, Dries D, Foster E, Gadegbeku CA et al. A longitudinal study of left ventricular function and structure from CKD to ESRD: the CRIC study. Clin J Am Soc Nephrol. 2013;8(3):355-62. https://doi.
org/10.2215/CJN.06020612

17. Silberberg JS, Barre PE, Prichard SS, Sniderman AD. Impact of left ventricular hypertrophy on survival in end-stage renal disease. Kidney Int. 1989;36(2):286-90. https://doi. org/10.1038/ki.1989.192

18. Tian JP, Wang T, Wang H, Cheng LT, Tian XK, Lindholm B et al. The prevalence of left ventricular hypertrophy in Chinese hemodialysis patients is higher than that in peritoneal dialysis patients. Renal failure. 2008;30(4):391-400. https://doi. org/10.1080/08860220801964178

19. ElloualiF,BerkchiF,BayahiaR,Benamar L, Cherti M. Comparison of the Effects of Dialysis Methods (Haemodialysis vs Peritoneal Dialysis) on Diastolic Left Ventricular Function Dialysis Methods and Diastolic Function. Open Cardiovasc Med J. 2016;10:171-8. https://doi. org/10.2174/1874192401610010171

20. Enia G, Mallamaci F, Benedetto FA, Panuccio V, Parlongo S, Cutrupi S et al. Long-term CAPD patients are volume expanded and display more severe left ventricular hypertrophy than haemodialysis patients. Nephrol Dial Transplant. 2001;16(7):1459-64. https:// doi.org/10.1093/ndt/16.7.1459

21. Yamada S, Ishii H, Takahashi H, Aoyama T, Morita Y, Kasuga H et al. Prognostic value of reduced left ventricular ejection fraction at start of hemodialysis therapy on cardiovascular and all-cause mortality in end-stage renal disease patients. Clin J Am Soc Nephrol. 2010;5(10):1793-98. https://doi.org/10.2215/CJN.00050110

22. Refaat H, Sany D, Mohab A, Ezzat H. Comparing Dialysis Modality and Cardiovascular Mortality in Patients on Hemodialysis and Peritoneal Dialysis. Adv Perit Dial. 2016;32:2231.Available from: https://www. advancesinpd.com/adv16/22-31_Refaat. pdf [Accessed 27th October 2020]

23. Alpert MA, Van Stone J, Twardowski ZJ, Ruder MA, Whiting RB, Kelly DL et al. Comparative cardiac effects 
of hemodialysis and continuous ambulatory peritoneal dialysis. Clin Cardiol. 1986;9(2):52-60. https://doi. org/10.1002/clc.4960090202

24. Peixoto AJ, Santos SF, Mendes RB, Crowley ST, Maldonado R, Orias M et al. Reproducibility Of ambulatory blood pressure monitoring in hemodialysis patients. Am J Kidney Dis. 2000;36(5):983-90. https://doi. org/10.1053/ajkd.2000.19100 